\title{
Can Endoscopists Become More Aggressive or Have More Options for Patients with Antithrombotic Agents?
}

\author{
Mitsuhiro Fujishiro
}

Published online: 6 April 2011

(C) Springer Science+Business Media, LLC 2011

Cardiovascular (CV) disease is a major cause of the loss of life as well as malignancy, especially in the developed countries, and the increasing use of antithrombotic agents in primary and secondary prophylaxis of $\mathrm{CV}$ events and/or after the implantation of an intravascular mechanical prosthesis have raised a concerns about the management of patients taking these agents during endoscopy [1]. Our Japanese case series revealed that approximately $15 \%$ of patients who underwent endoscopy were receiving these agents in recent years, although the proportion may be less than that of Western countries [2]. Following these trends, the British Society of Gastroenterology (BSG) and the American Society for Gastrointestinal Endoscopy (ASGE) have independently modified and issued their guidelines for the management of antithrombotic agents during endoscopy in 2008 and 2009, respectively [3, 4]. According to these guidelines, all of the endoscopic procedures can be performed without cessation of non-steroidal antiinflammatory drugs (NSAIDs) or aspirin, and those with low bleeding risk can be performed without cessation of thienopyridine derivatives such as ticlopidine and clopidogrel and anticoagulants such as warfarin. In terms of procedures with high bleeding risk, a certain period of cessation (e.g., 7-10 days for thienopyridine and 3-5 days for warfarin) is recommended before undertaking the procedures (Table 1).

On the other hand, endoscopists in Japan, where it is believed that endoscopy is the most widespread procedure,

M. Fujishiro $(\bowtie)$

Department of Endoscopy and Endoscopic Surgery,

Graduate School of Medicine, The University of Tokyo,

7-3-1, Hongo, Bunkyo-ku, Tokyo, Japan

e-mail: mtfujish-kkr@umin.ac.jp have followed a guideline from the Japan Gastroenterological Endoscopy Society (JGES), issued in 2005 [5], with slightly different management from that of the rest of world. According to the Japanese guideline, it is necessary to stop all of the antithrombotic agents, regardless of their antithrombotic mechanism, even for procedures with low bleeding risk, excluding for diagnostic endoscopy without biopsy. Ceased durations of aspirin alone, thienopyridine derivatives alone, both aspirin and thienopyridine, and warfarin are recommended at 3, 5, 7, and 3-4 days, respectively, regardless of the bleeding risks of procedures. So it is quite a common situation for patients to stop undergoing antithrombotic agents for a while in order to have another endoscopy a few weeks after diagnostic endoscopy in order to take a biopsy, polypectomy, and so on. When the patient has a high thromboembolic risk, it is required to hospitalize them to replace antithrombotic agents with heparin, even for taking a biopsy.

Many endoscopists in Asian countries have been influenced by the Japanese guideline, so there is a big difference between the East and the West in terms of attitudes and practices of endoscopists, which were well outlined by Lee et al. [6]. More Western endoscopists perform biopsy on warfarin or polypectomy on aspirin, whereas more Eastern endoscopists consider that bleeding risks and thromboembolic risks are higher in Asians and Caucasians, respectively, without solid evidence. However, we have to mention that these opinions are not obtained by clinical studies in the literature comparing the different rates of complications of endoscopy between the East and the West. Furthermore, the survey also revealed, interestingly, that personal experience seemed to be a more powerful driver of practice than the published guidelines, even among Western endoscopists. Our multicenter questionnaire in Japan also revealed the low permeation of the 
Table 1 Differences between the guidelines for antithrombotic agents during endoscopy

\begin{tabular}{|c|c|c|}
\hline & Low bleeding risk procedure & High bleeding risk procedure (e.g., polypectomy) \\
\hline BSG & Continue & $\begin{array}{l}\text { Continue aspirin } \\
\text { Discontinue thienopyridines } 7 \text { days } \\
\text { Discontinue warfarin } 5 \text { days }\end{array}$ \\
\hline ASGE & Continue & $\begin{array}{l}\text { Continue aspirin } \\
\text { Discontinue thienopyridines } 7-10 \text { days } \\
\text { Discontinue warfarin } 3-5 \text { days }\end{array}$ \\
\hline JGES & $\begin{array}{l}\text { Discontinue aspirin } 3 \text { days } \\
\text { Discontinue thienopyridines } 5 \text { days } \\
\text { Discontinue both of the above } 7 \text { days in case of dual therapy } \\
\text { Discontinue warfarin } 3-4 \text { days }\end{array}$ & Same as the low bleeding risk procedure \\
\hline
\end{tabular}

ASGE American Society for Gastrointestinal Endoscopy, BSG British Society of Gastroenterology, JGES Japan Gastroenterological Endoscopy Society

Japanese guideline [7], which might be caused by the fact that major parts of these guidelines were established by experts' opinions or limited studies with low evidence level.

Colonoscopic polypectomy, which is classified as a procedure with a high bleeding risk, requires to stop thienopyridine derivatives or warfarin even, in Western guidelines [3, 4]. However, Singh et al. cast doubt on the necessity of the routine cessation of clopidogrel for colonoscopic polypectomy, because the independent risk factors in the patients taking clopidogrel, who had more occurrences of post-polypectomy bleeding (PPB) $(3.5 \%)$ than the control patients $(1.0 \%)$, were the number of resected polyps and concomitant use of NSAIDs and/or aspirin, but not the use of clopidogrel alone [8]. The study by Feagins et al. described in this issue of Digestive Diseases and Sciences highlighted again the relationship between PPB and clopidogrel [9]. According to their policy that the adverse $\mathrm{CV}$ events of stopping clopidogrel may outweigh the benefits in preventing PPB, they principally performed colonoscopic polypectomy without cessation of clopidogrel, which revealed that the PPB rates did not differ significantly between patients with and without clopidogrel. However, the data have to be carefully interpreted before application in our daily practice as they discussed. First, the majority of polyps were less than $1 \mathrm{~cm}$ in size and were treated by cold forceps. So it is a little controversial to judge the procedural risk for small polyps which were treatable by cold forceps to be a high bleeding risk. Second, hemoclips were used more often for the patients taking clopidogrel $(22 \%)$, which was much more often in comparison with that in the previous study $(4.2 \%)$ by Singh et al. [8], although it was revealed that prophylactic clip placement in patients without antithrombotic agents did not decrease the occurrence of PPB for small polyps of less than $1 \mathrm{~cm}$ in size [10]. These or other considerable limitations of their study must be clarified by the upcoming studies in the future, one of which should be a prospective randomized controlled trial to compare groups continuing and groups discontinuing clopidogrel. Similar clinical questions may be raised for warfarin or other procedures with a high bleeding risk for the patients taking clopidogrel as the next agenda.

Now, can we become more aggressive for patients taking clopidogrel? The answer must be "no." The major clinical indications of clopidogrel are the prevention of arterial thromboembolism in patients with atherosclerosis, e.g., peripheral vascular disease, myocardial infarction, or thromboembolic stroke, and the prevention of occlusion of coronary artery stents [3]. Clopidogrel alone is used mainly for the former and also for the latter after a certain period of placement. When the patients do not have high thromboembolic risk which requires concomitant aspirin use, tentative cessation for endoscopy may be possible without increasing $\mathrm{CV}$ events. So, it may be more beneficial for such patients to stop clopidogrel before colonic polypectomy. In fact, $21 \%$ of the patients taking clopidogrel in the study by Feagins et al. did not have the dual therapy, and, even in the case of dual therapy, it might be possible to postpone the screening or surveillance colonoscopy itself (more than half of colonoscopies in the clopidogrel group were performed by this indication) until the dual therapy was no longer required [9]. I hope that the accumulated knowledge will be used for the patients themselves and I would like to stress the most acceptable policy of medicine, which is estimation of the risks and the benefits tailored to individual patients from a standpoint of patients. We may just have another option to perform colonoscopic polypectomy without cessation of clopidogrel from the wonderful study [9]. 


\section{References}

1. Becker RC, Scheiman J, Dauerman HL, et al. Management of platelet-directed pharmacotherapy in patients with atherosclerotic coronary artery disease undergoing elective endoscopic gastrointestinal procedures. Am J Gastroenterol. 2009;104:2903-2917.

2. Ono S, Fujishiro M, Kodashima S, et al. Controversy on the management of anticoagulants and antiplatelet agents for scheduled endoscopy. Dig Endosc. 2011;23:1-4.

3. Veitch AM, Baglin TP, Gershlick AH, et al. Guidelines for the management of anticoagulant and antiplatelet therapy in patients undergoing endoscopic procedures. Gut. 2008;57:1322-1329.

4. ASGE Standards of Practice Committee. Management of antithrombotic agents for endoscopic procedures. Gastrointest Endosc. 2009; 70:1060-1070.

5. Ogoshi K, Kaneko E, Tada M, et al. The management of anticoagulation and antiplatelet therapy for endoscopic procedures. Gastroenterol Endosc. 2005;47:2691-2695.
6. Lee SY, Tang SJ, Rockey DC, et al. Managing anticoagulation and antiplatelet medications in GI endoscopy: a survey comparing the East and the West. Gastrointest Endosc. 2008;67:1076-1081.

7. Fujishiro M, Oda I, Yamamoto Y, et al. Multi-center survey regarding the management of anticoagulation and antiplatelet therapy for endoscopic procedures in Japan. $J$ Gastroenterol Hepatol. 2009;24:214-218.

8. Singh M, Mehta N, Murthy UK, et al. Postpolypectomy bleeding in patients undergoing colonoscopy on uninterrupted clopidogrel therapy. Gastrointest Endosc. 2010;71:998-1005.

9. Feagins LA, Udin FS, Davila RE, et al. The rate of post-polypectomy bleeding for patients on uninterrupted clopidogrel therapy during elective colonoscopy is acceptably low. Dig Dis Sci. (Epub ahead of print). doi:10.1007/s10620-011-1682-2.

10. Shioji K, Suzuki Y, Kobayashi M, et al. Prophylactic clip application does not decrease delayed bleeding after colonoscopic polypectomy. Gastrointest Endosc. 2003;57:691-694. 